Check for updates

Cite this: Phys. Chem. Chem. Phys.,

2021, 23, 4544

Received 15th December 2020,

Accepted 6th February 2021

DOI: 10.1039/d0cp06497a

rsc.li/pccp

\section{The defect chemistry of non-stoichiometric $\mathrm{PuO}_{2 \pm x}$}

\author{
William D. Neilson, (DD ${ }^{a}$ James T. Pegg, ${ }^{\text {bc }}$ Helen Steele ${ }^{d}$ and Samuel T. Murphy (D) *a
}

An increased knowledge of the chemistry of $\mathrm{PuO}_{2}$ is imperative for the design of procedures to store, dispose, or make use of $\mathrm{PuO}_{2}$. In this work, point defect concentrations in $\mathrm{PuO}_{2}$ are determined by combining density functional theory (DFT) defect energies and empirical potential calculations of vibrational entropies. The obtained defect concentrations are expressed as a function of temperature and oxygen partial pressure and used to calculate non-stoichiometry in $\mathrm{PuO}_{2 \pm x}$. The results show that the defect chemistry of $\mathrm{PuO}_{2}$ is dominated by oxygen vacancies and interstitials. Hypo-stoichiometric $\mathrm{PuO}_{2-x}$ is accommodated by both the uncharged oxygen vacancy $\left(\mathrm{V}_{\mathrm{O}}^{\times}\right)$and positively charged oxygen vacancy $\left(\mathrm{V}_{\mathrm{O}}^{2+}\right)$ at small values of $x$, with $\mathrm{V}_{\mathrm{O}}^{\times}$increasingly dominant with increasing $x$. The negatively charged oxygen interstitial $\left(\mathrm{O}_{\mathrm{i}}^{2-}\right)$ is found to accommodate hyper-stoichiometry $\left(\mathrm{PuO}_{2+x}\right)$, but reluctance to form hyper-stoichiometric $\mathrm{PuO}_{2+x}$ is observed, with oxygen interstitials present only in very low concentrations irrespective of conditions. The small degree of hyper-stoichiometry found is favoured by low temperatures.

\section{Introduction}

The handling, storage and disposal of $\mathrm{PuO}_{2}$ (the form civilian plutonium stockpiles are maintained in) ${ }^{1}$ presents considerable safety and security challenges. Large stockpiles of $\mathrm{PuO}_{2}$ currently exist in interim storage awaiting decisions regarding its longterm disposal or re-use; $\mathrm{PuO}_{2}$ attracts interest as a component of future nuclear reactor fuels and ${ }^{238} \mathrm{Pu}$, in the form ${ }^{238} \mathrm{PuO}_{2}$, is the most commonly used isotope in radioisotope thermoelectric generators and heating units for space applications. ${ }^{2}$ To enable safe storage and/or application a thorough understanding of how the material evolves in the short to medium term is required, which can be aided by studying the materials defect chemistry.

The potential pressurisation of some of the containers used to store $\mathrm{PuO}_{2}$ is of major concern, with multiple pressurisation mechanisms proposed. ${ }^{3}$ The formation of hyper-stoichiometric $\mathrm{PuO}_{2+x}$ may play a role in the chemical reactions producing gas. It is reported that $\mathrm{PuO}_{2+x}$ participates in moisture enhanced corrosion of $\mathrm{Pu}$, producing $\mathrm{H}_{2},{ }^{4-6}$ although this is less of a concern in the UK, where the oxide is stored. Through experimental

\footnotetext{
${ }^{a}$ Engineering Department, Lancaster University, Lancaster, LA1 4YW, UK.

E-mail: samuel.murphy@lancaster.ac.uk

${ }^{b} 1$ QB Information Technologies (1QBit), Vancouver, British Columbia,

V6E 4B1, Canada

${ }^{c}$ Department of Chemistry, University College London, 20 Gordon Street,

London WC1H OAJ, UK

${ }^{d}$ Sellafield Ltd, Sellafield, Cumbria, CA20 1PG, UK
}

investigation of $\mathrm{PuO}_{2}$ at conditions relevant to intermediate storage, Haschke et $a l^{4,5}$ have reported the existence of the hyper-stoichiometric $\mathrm{PuO}_{2+x}$ phases, while subsequent work has shown $\mathrm{PuO}_{2+x}$ may be best described as a compound containing $\mathrm{OH}^{-}$and $\mathrm{H}_{2} \mathrm{O}$ species, with excess oxygen accommodated in molecular complexes of $\mathrm{Pu}(\mathrm{v})^{7,8}$ The defect chemistry of $\mathrm{PuO}_{2}$ helps describe the formation and properties of non-stoichiometric $\mathrm{PuO}_{2}$ and the equilibrium of species (e.g. oxygen) between the $\mathrm{PuO}_{2}$ solid and the surrounding gases.

$\mathrm{PuO}_{2}$ is very challenging to study both experimentally and theoretically. Experimental challenges include strict regulation, the difficulty in preparing and handling samples, and continuous crystal lattice damage and transmutation of $\mathrm{Pu}$ due to selfirradiation. ${ }^{9}$ Many of the challenges involved in theoretical calculation arise from trying to correctly describe the 5 f electrons. $\mathrm{PuO}_{2}$ is classified as a strongly correlated material, with a ground state of localised $5 f$ electrons. ${ }^{10}$ In conventional density functional theory (DFT), an over de-localisation of these electrons results in the selfinteraction error that causes $\mathrm{PuO}_{2}$ to be described as conducting when in fact $\mathrm{PuO}_{2}$ is classified as a charge-transfer insulator. ${ }^{10}$

A method used extensively to overcome this shortcoming is to adopt a Hubbard-like correction to give the DFT $+U$ method. ${ }^{10}$ The $U$ parameter modifies the electron repulsion of the $5 \mathrm{f}$ electrons and addresses the self-interaction error, yielding good reproduction of the ground-state electronic properties seen in actinide dioxides. ${ }^{10,11}$ Two adjustable variables help construct the $U$ correction parameter. These are the on-site Coulombic $(U)$ and exchange interaction $(J)$ parameters, which are used to 
calculate $U_{\text {eff }}=U-J$ in the Dudarev et al. formulism. ${ }^{12}$ The $U$ and $J$ parameters are obtained by fitting to structural and electronic properties of $\mathrm{PuO}_{2} \cdot{ }^{11,13-17}$ Reproduction of the electronic band gap $\left(E_{\mathrm{g}}\right)$ is seen as a strong metric of success. Most previous DFT $+U$ studies of $\mathrm{PuO}_{2}$ fit $U$ and $J$ to reproduce the bandgap of McNeilly et $a .^{18}\left(E_{\mathrm{g}}=1.8 \mathrm{eV}\right)$, however the much more recent experimental study of McCleskey et al. ${ }^{19}$ reports a higher $E_{\mathrm{g}}$ of $2.8 \mathrm{eV}$. This large discrepancy in the experimental bandgap for $\mathrm{PuO}_{2}$ poses significant issues for determination of the appropriate values for $U$ and $J$.

An alternative method to $\mathrm{DFT}+U$ used to avoid the problems encountered with the self-interaction error is to use hybrid functionals. Hybrid functionals, which blend a portion of the Hartree-Fock (HF) exchange into a part of a density functional, have been shown to offer significantly improved descriptions of band gaps, especially in small- to medium- gap systems $(\sim<5 \mathrm{eV}) .{ }^{20}$ Compared to the $\mathrm{DFT}+U$ method, hybrid functionals require significantly more computational effort to utilise, but several studies have applied hybrid functionals to study $\mathrm{PuO}_{2}$ with good experimental replication achieved. ${ }^{14,21}$

An important aspect in correctly simulating $\mathrm{PuO}_{2}$ is selection of an accurate description of its magnetic ground state. Experimental and theoretical studies have indicated differing ground states: a singlet diamagnetic (DM) ground-state is indicated from experimental observations ${ }^{22}$ whereas ferromagnetic (FM) or anti-ferromagnetic (AFM) ground states have in the past been predicted from theory. ${ }^{14,17,21,23}$ Many studies select 1k AFM order to describe $\mathrm{PuO}_{2} \cdot{ }^{13,17,21,24-26}$ In their comprehensive study of magnetic order in $\mathrm{PuO}_{2}$, Pegg et al. ${ }^{14}$ found that $1 \mathrm{k}$ AFM states produce an incorrect crystal structure (the correct structure as indicated by experimental results is $F m \overline{3} m$ crystal symmetry ${ }^{27}$ and that the choice of AFM domain (longitudinal or transverse) had a significant impact on the electronic and structural properties of $\mathrm{PuO}_{2}$. This is a key finding, as most studies do not differentiate between collinear magnetic structures. Pegg et al. ${ }^{14}$ propose a longitudinal 3k AFM ground-state. Of all magnetic configurations tested, this was the lowest in energy, was able to retain $F m \overline{3} m$ crystal symmetry and replicated well the physical properties of $\mathrm{PuO}_{2}$.

To obtain this ground-state, spin orbit interaction (SOI) was included. Not including SOI resulted in a different magnetic ground state being obtained, highlighting the importance of its inclusion. The different observations found in experiment are perhaps a consequence of the aforementioned experimental challenges. Possible theories include that current experimental resolution cannot identify an ordered magnetic state and/or an AFM-DM transition could be occurring outside the temperature ranges investigated. ${ }^{14}$ The experimental measurement of isostructural $\mathrm{NpO}_{2}$ has also proven difficult, where an odd number of electrons should result in a magnetic moment.

Several studies have investigated the formation energies of intrinsic and extrinsic defects in $\mathrm{PuO}_{2} \cdot{ }^{24,26,28-33}$ Thermochemical models have been produced that study the defect chemistry of $\mathrm{PuO}_{2-x}$, over a large stoichiometry range, ${ }^{34,35}$ whilst using $\mathrm{DFT}+U$ and a point defect model, Lu et al. ${ }^{24}$ determined the stability of charged defects within $\mathrm{PuO}_{2 \pm x}$. Lu et al. ${ }^{24}$ find that, at
$1000 \mathrm{~K}$, oxygen vacancies dominate in the region of hypostoichiometry, whilst oxygen interstitials dominate the region of hyper-stoichiometry.

It is common when creating a point defect model from first principles to assume that the Gibbs free energy to form a defect can be well approximated by the defect formation energy. However, this approximation neglects the contribution of the

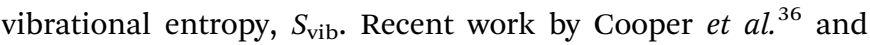
Soulie et al. ${ }^{37}$ on $\mathrm{UO}_{2}$ has shown that it is only by including the change in vibrational entropy due to defect incorporation that it is possible to reproduce the defect chemistry observed in experiment.

Therefore, the objective of this paper is to understand the defect chemistry of $\mathrm{PuO}_{2}$ and how it might evolve under storage conditions taking into account the complex electronic and magnetic structures and incorporating the vibrational entropy into an updated point defect model.

\section{Method}

To determine how the concentrations of defects in $\mathrm{PuO}_{2}$ varies with environmental conditions requires the combination of DFT defect energies and simple thermodynamics, starting from eqn (1). Using Boltzmann statistics, this equation shows that the concentration of defect $i, c_{i}$, can be related to the change in Gibbs free energy, $\Delta G_{\mathrm{f}}^{i}$, to form defect $i$ :

$$
c_{i}=m_{i} \exp \left(\frac{-\Delta G_{\mathrm{f}}^{i}}{k_{\mathrm{B}} T}\right)
$$

where $m_{i}$ is the multiplicity of equivalent sites, $k_{\mathrm{B}}$ is the Boltzmann constant and $T$ is the temperature. $\Delta G_{\mathrm{f}}^{i}$ is defined as:

$$
\Delta G_{\mathrm{f}}^{i}=\Delta E-T \Delta S_{\mathrm{vib}} \pm \sum_{\alpha} n_{\alpha} \mu_{\alpha}+q_{i} \mu_{e}+E_{\mathrm{corr}}
$$

where $\Delta E$ is the defect energy: the difference in the total DFTderived energies of the defective and perfect supercells. $\Delta S_{\text {vib }}$ is the difference in vibrational entropy between defective and perfect supercells. Within the third term, $n_{\alpha}$ is the number of atoms of species, $\alpha$, added or removed from the system to make defect $i$, where $\mu_{\alpha}$ is the chemical potential of species $\alpha . q_{i}$ is the charge of the defect $i$, and $\mu_{\mathrm{e}}$ is the electron chemical potential. Finally, $E_{\text {corr }}$ is a correction term necessary to correct for finitesize effects arising due to the use of relatively small simulation supercells.

Following Cooper et $a l .{ }^{36}$ and Soulie et al., ${ }^{37}$ two differing atomistic simulation approaches were applied to obtain the parameters of eqn (2): $\Delta E$ is found using DFT and $\Delta S_{\text {vib }}$ is obtained using empirical pair potentials. The vibrational entropy of a lattice is a function of the lattices phonon frequencies which are determined through force calculations associated with the displacements of atoms from their ground state positions. This becomes a very large calculation when defects are introduced, due to the removal of symmetry. Therefore, empirical potentials are used to calculate the vibrational entropies. 

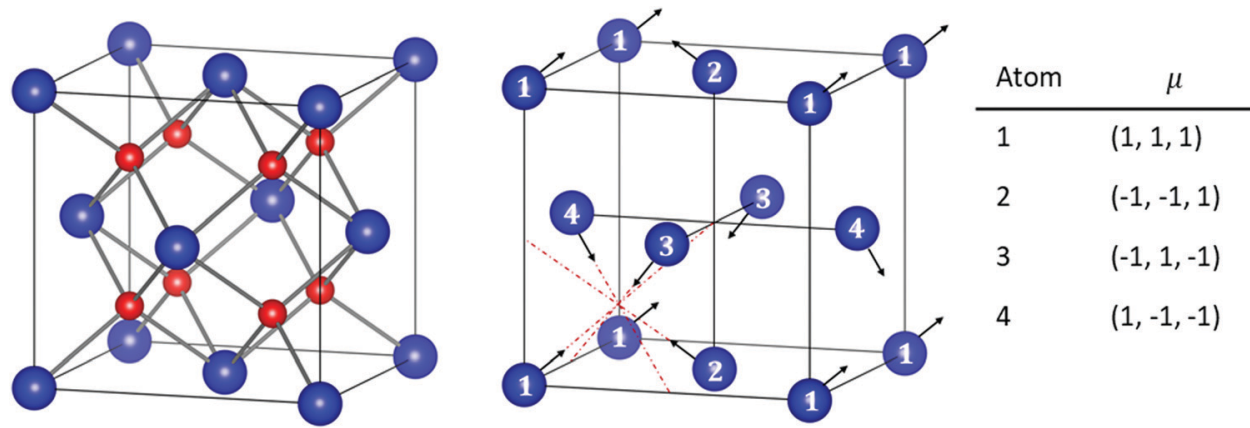

Fig. 1 The crystal (left) and magnetic (centre) structure of $\mathrm{Fm} \overline{3} \mathrm{~m} \mathrm{PuO}_{2}$, with plutonium and oxygen atoms depicted with blue and red spheres respectively. The direction of the effective magnetic moment $(\mu)$ on each plutonium ion is shown by an arrow and the $\mu=(a, b, c)$ wave-vector matrix (right).

The calculation and use of all the terms that contribute to eqn (2) are discussed in more detail throughout the rest of this section.

\subsection{Defect energies}

DFT calculations were performed using the Vienna $a b$ initio Simulation Package (VASP). ${ }^{38-41}$ The projector augmented wave $(\mathrm{PAW})^{42,43}$ method has been implemented with the frozen-core approximation. $5 f^{4} 6 s^{2} 6 p^{6} 6 d^{2} 7 s^{2}$ of $\mathrm{Pu}$ and $1 s^{2} 2 s^{2} 2 p^{6}$ of $\mathrm{O}$ are treated as valence electrons. Following convergence testing, the cut-off energy for the planewave basis set was selected to be $500 \mathrm{eV}$ and a $4 \times 4 \times 4$ Monkhurst-Pack $k$-point mesh ${ }^{44}$ was used for the 12-atom $\mathrm{PuO}_{2}$ unit cells. For $2 \times 2 \times 2$ supercells used in defect simulations, the $k$-point mesh was adjusted to $2 \times 2 \times 2$. SOI $^{45}$ was considered in the calculations with a longitudinal 3k AFM magnetic configuration adopted for $\mathrm{PuO}_{2}$, described in Fig. 1.

To study the properties of the bulk $\mathrm{PuO}_{2}$, we replicate the study of Pegg et $a .^{14}$ and use the hybrid Heyd-ScuseriaErnzerhof (HSE06) functional: ${ }^{46-49}$

$$
E_{\mathrm{XC}}^{\mathrm{HSE}}=\frac{1}{4} E_{\mathrm{X}}^{\mathrm{HF}, \mathrm{SR}}(\mu)+\frac{3}{4} E_{\mathrm{X}}^{\mathrm{PBE}, \mathrm{SR}}(\mu)+E_{\mathrm{X}}^{\mathrm{PBE}, \mathrm{LR}}(\mu)+E_{\mathrm{C}}^{\mathrm{PBE}}
$$

where $E_{\mathrm{XC}}^{\mathrm{HSE}}$ is the exchange-correlation HSE06 energy, $E_{\mathrm{X}}^{\mathrm{HF}, \mathrm{SR}}$ is the short-range $\mathrm{HF}$ exchange, $E_{\mathrm{X}}^{\mathrm{PBE}, \mathrm{SR}}$ and $E_{\mathrm{X}}^{\mathrm{PBE}, \mathrm{LR}}$ are the shortrange and long-range components of the Perdew-Burke-Ernzerhof (PBE) exchange functional respectively and $E_{\mathrm{C}}^{\mathrm{PBE}}$ is the PBE correlation energy. A quarter of the short-range HF exchange is used in this functional and the screening parameter $(\mu)$ is $0.207 \AA^{-1}$. The iteration threshold for electronic and ionic convergence when using this functional is $1 \times 10^{-6} \mathrm{eV}$ and $1 \times 10^{-2} \mathrm{eV} \AA^{-1}$, respectively.

For calculation of defect energies in $\mathrm{PuO}_{2}$ supercells hybrid functionals are computationally too expensive; DFT calculations are therefore performed with the generalised gradient approximation (GGA) using the PBE functional revised for solids (PBEsol). ${ }^{50,51}$ The PBEsol functional was shown by Pegg et al. ${ }^{11}$ to best reproduce experimental properties in actinide dioxides after the HSE06 functional. The strong correlations due to f-electrons in $\mathrm{Pu}$ were accounted for by applying the $\mathrm{DFT}+U$ method using the Liechtenstein formulism. ${ }^{52}$ When using PBEsol $+U$, the iteration threshold for electronic convergence is
$1 \times 10^{-6} \mathrm{eV}$ and for ionic convergence is $1 \times 10^{-2} \mathrm{eV} \AA^{-1}$ and $2 \times 10^{-2} \mathrm{eV} \AA^{-1}$ when simulating $\mathrm{PuO}_{2}$ unit cells and defect containing $\mathrm{PuO}_{2}$ supercells, respectively. In this study, the $U$ parameter within PBEsol $+U$ was selected such that it reproduced the band gap obtained from the HSE06 functional $(3.04 \mathrm{eV})$. It was chosen to reproduce the HSE06 bandgap as the experimental data shows a large variation and this functional has been proven to replicate experimental bandgaps. ${ }^{20}$ This resulted in a $U$ parameter of $7.0 \mathrm{eV}$ being used for this study (see Fig. 2). The use of a high $U$ parameter is not without precedence, with several previous studies adopting $U$ values exceeding $6.0 \mathrm{eV}$ when studying actinide dioxides, including $\mathrm{PuO}_{2} \cdot{ }^{11,53}$ The $J$ parameter was fixed at a value of $0.0 \mathrm{eV}$ throughout this study, as any introduction of $J$ was shown by Pegg et al. ${ }^{11}$ to detrimentally affect the reproduction of the band gap for $\mathrm{PuO}_{2}$. The resulting equilibrium properties found for longitudinal 3k AFM $\mathrm{PuO}_{2}$ simulated using either the HSE06 functional or PBEsol $+U(U=7.0 \mathrm{eV})$ are presented in Table 1. The discrepancy between the theoretical and experimental description of the magnetic properties of $\mathrm{PuO}_{2}$ is discussed in the introduction.

Defects were inserted into $2 \times 2 \times 2$ expansions of the 12-atom $\mathrm{PuO}_{2}$ unit cell. Only one unique site exists for the vacancies and interstitials of plutonium and oxygen considered,

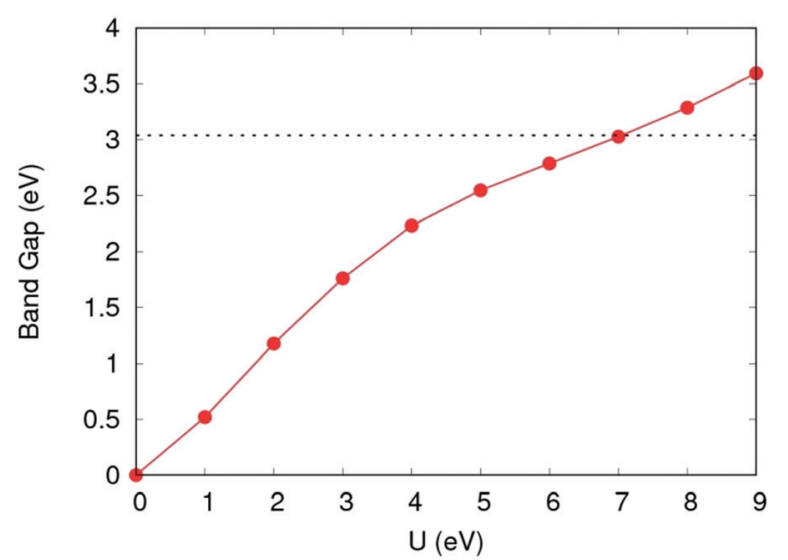

Fig. 2 Variation of band gap as a function of the Coulomb modifier (U). Band gap value calculated using the HSEO6 functional shown with horizontal dotted line. 
Table 1 The lattice constant ( $\AA$ ), magnetic moment ( $\mu_{\mathrm{B}} / \mathrm{Pu}$ ion), band gap energy (eV) and crystal symmetry for longitudinal $3 \mathrm{~K}$ AFM PuO $\mathrm{O}_{2}$ calculated using either the HSEO6 functional or PBEsol $+U(U=7.0 \mathrm{eV})$. In addition, we show reported experimental values

\begin{tabular}{|c|c|c|c|c|c|c|}
\hline & & Lattice constant $(\AA)$ & Magnetic moment ( $\mu_{\mathrm{B}} / \mathrm{Pu}$ ion $)$ & Band gap (eV) & Crystal symmetry & Magnetic configuration \\
\hline & PBEsol $+U$ & 5.415 & 3.82 & 3.03 & $F m \overline{3} m$ & Longitudinal 3k AFM \\
\hline
\end{tabular}

due to the symmetry of the $\mathrm{PuO}_{2}$ lattice. Different charge states were considered for each defect, modelled by adding or removing electrons from the supercell. Defect-containing supercells were relaxed under constant volume, using the lattice constants obtained from defect-free simulations. The defects considered in this study are denoted below, using Kröger-Vink notation, modified to display charge as an integer value (no charge indicated by: $\times$ ): ${ }^{54}$

Oxygen interstitials: $\mathrm{O}_{\mathrm{i}}{ }^{\times}, \mathrm{O}_{\mathrm{i}}^{1-}$ and $\mathrm{O}_{\mathrm{i}}^{2-}$

Oxygen vacancies: $\mathrm{V}_{\mathrm{O}}^{\times}, \mathrm{V}_{\mathrm{O}}^{1+}$ and $\mathrm{V}_{\mathrm{O}}^{2+}$

Plutonium interstitials: $\mathrm{Pu}_{\mathrm{i}}^{\times}, \mathrm{Pu}_{\mathrm{i}}^{1+}, \mathrm{Pu}_{\mathrm{i}}^{2+}, \mathrm{Pu}_{\mathrm{i}}^{3+}$ and $\mathrm{Pu}_{\mathrm{i}}^{4+}$

Plutonium vacancies: $\mathrm{V}_{\mathrm{Pu}}^{\times}, \mathrm{V}_{\mathrm{Pu}}^{1-}, \mathrm{V}_{\mathrm{Pu}}^{2-}, \mathrm{V}_{\mathrm{Pu}}^{3-}$ and $\mathrm{V}_{\mathrm{Pu}}^{4-}$

\subsection{Finite size correction}

The introduction of charged defects into the small simulation supercells accessible using DFT introduces a number of finite size effects as discussed extensively in ref. 55 . These include Coulombic interactions between the defect and its periodic image as well as with the neutralising background charge. The result is that defect formation energies exhibit a strong dependence on the size of the supercell used and this must be corrected for. The most basic correction that can be applied to remove these interactions is the point charge (PC) correction. For a cubic system, such as $\mathrm{PuO}_{2}$, the PC correction energy can be written as: ${ }^{56}$

$$
E_{\mathrm{PC}}^{\text {iso }}=\frac{\alpha q^{2}}{2 \varepsilon L}
$$

where $\alpha=2.837$ is the lattice-type dependent Madelung constant, $L$ is the supper cell lattice constant and $\varepsilon$ is the static dielectric constant. The static dielectric constant of $\mathrm{PuO}_{2}$ was calculated using density functional perturbation theory (DFPT) ${ }^{57,58}$ as

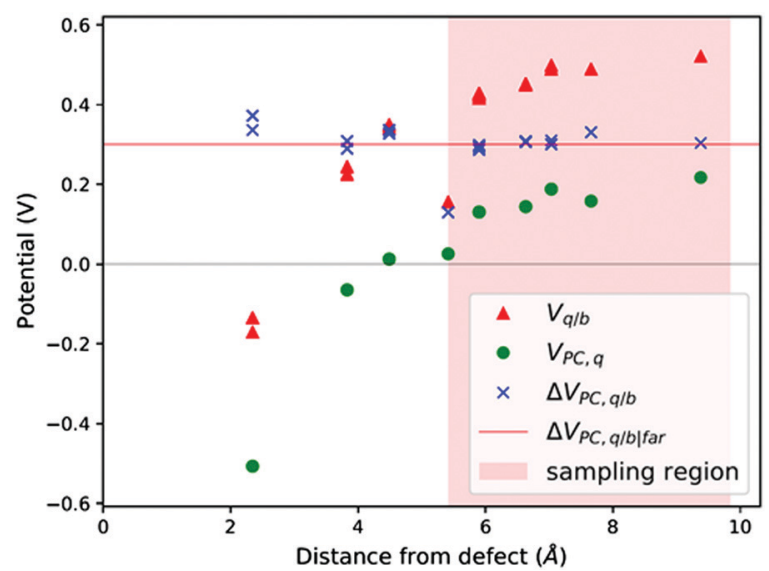

Fig. $3 V_{\mathrm{q} / \mathrm{b}}, V_{\mathrm{PC}, \mathrm{q}}$ and $\Delta V_{\mathrm{PC}, \mathrm{q} / \mathrm{b}}$ calculated at the atomic positions of a $\mathrm{PuO}_{2}$ supercell with a $V_{\mathrm{Pu}}^{4-}$ defect. $\Delta V_{\mathrm{PC}, \mathrm{q} / \mathrm{b}}$ far $_{\text {far }}$ calculated by averaging $\Delta V_{\mathrm{PC}, \mathrm{q} / \mathrm{b}}$ across sampling region. implemented in VASP. We use the previously described longitudinal 3k $\mathrm{AFM} \mathrm{PuO}_{2}$ unit cell with PBEsol $+U(U=7.0 \mathrm{eV})$. The static dielectric tensor of $\mathrm{PuO}_{2}, \varepsilon_{i j}$ is calculated by summing its electronic and ionic components. The average of the static dielectric tensor, $\frac{1}{3} \operatorname{Tr}\left(\varepsilon_{i j}\right)$ is calculated and used as the static dielectric constant of $\mathrm{PuO}_{2}$. We obtain a static dielectric constant of 19.66. This compares favourably to the experimental value $\left(18.9^{59}\right)$ and falls between the experimental value for $\mathrm{UO}_{2}\left(23.8^{60}\right)$ and the DFTobtained value for $\mathrm{AmO}_{2}\left(17.40^{61}\right)$, thus fits within the emerging trend.

Makov and Payne (MP) extended the PC correction to include a term with $L^{-3}$ order. ${ }^{62}$ More recently Freysoldt, Neugebauer and Van de Walle (FNV) developed a correction that compares the planar-averaged electrostatic potentials of supercells with and without defects ( $V_{\text {defect,q }} \& V_{\text {bulk }}$ respectively).$^{63}$ The FNV scheme correction energy is summarised following ref. 64 as:

$$
\begin{gathered}
E_{\mathrm{corr}}=E_{\mathrm{PC}}^{\mathrm{iso}}-\left.q \Delta V_{\mathrm{PC}, \mathrm{q} / \mathrm{b}}\right|_{\text {far }} \\
V_{\mathrm{q} / \mathrm{b}}=V_{\text {defect }, \mathrm{q}}-V_{\mathrm{bulk}} \\
\Delta V_{\mathrm{PC}, \mathrm{q} / \mathrm{b}}=\mathrm{V}_{\mathrm{q} / \mathrm{b}}-V_{\mathrm{PC}, \mathrm{q}}
\end{gathered}
$$

$\Delta V_{\mathrm{PC}, \mathrm{q} / \mathrm{b}}$ is the potential difference between the defect induced potential $\left(V_{\mathrm{q} / \mathrm{b}}\right)$ and the PC potential $\left.V_{\mathrm{PC}, \mathrm{q}} \cdot{ }^{63} \Delta V_{\mathrm{PC}, \mathrm{q} / \mathrm{b}}\right|_{\text {far }}$ is $\Delta V_{\mathrm{PC}, \mathrm{q} / \mathrm{b}}$ at a position far from the defect site but still within the supercell. The FNV scheme has been demonstrated to be an effective correction in many systems ${ }^{65}$ however the use of planar-averaged electrostatic potentials can provide unreliable corrections when the atomic positions of the defective supercell are allowed to relax. This was observed in the system investigated in this study: with the example of a $\mathrm{V}_{\mathrm{Pu}}^{4-}$ supercell, $\left.V_{\mathrm{PC}, \mathrm{q} / \mathrm{b}}\right|_{\text {far }}$ could not be determined accurately as $V_{\mathrm{q} / \mathrm{b}}$ was seen to strongly fluctuate whilst $V_{\mathrm{PC}, \mathrm{q}}$ remains parabolic (illustration in appendix). Consequently, this study employs the correction of Kumagai and Oba which uses atomic site electronic potentials as opposed to planar averaged electrostatic potentials. ${ }^{64}$ Using the same example of a $V_{\mathrm{Pu}}^{4-}$ supercell, Fig. 3 shows that this scheme is able to produce $\left.\Delta V_{\mathrm{PC}, \mathrm{q} / \mathrm{b}}\right|_{\text {far }}$ that is close to constant across the sampling region. Kumagai and Oba also demonstrate that a potential alignment correction, sometimes adopted to shift the valence band maximum of a charged defect to that of a pristine host, is not required. ${ }^{64}$ The difference in $\Delta E$ between a $\mathrm{V}_{\mathrm{Pu}}^{4-} 3 \times 3 \times 3$ supercell and a $\mathrm{V}_{\mathrm{Pu}}^{4-} 2 \times 2 \times 2$ supercell was found to decrease from $1.29 \mathrm{eV}$ when no correction was applied to $0.06 \mathrm{eV}$ after correction following the Kumagai and Oba scheme. This gives confidence that the correction works well for the system studied here. 


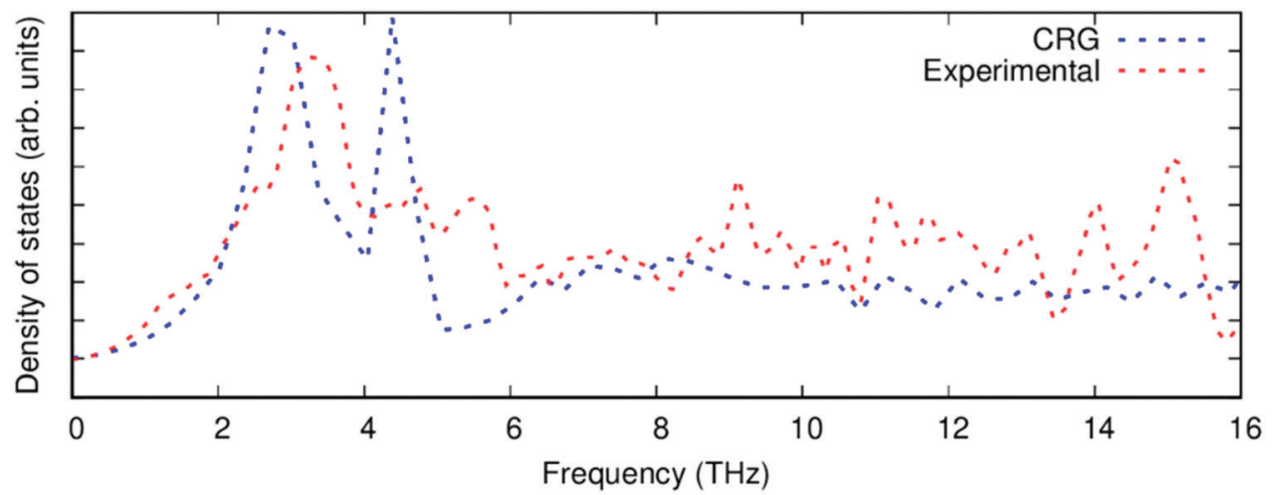

Fig. 4 The phonon density of states of $\mathrm{PuO}_{2}$ calculated with the $\mathrm{CRG}$ empirical potential (blue), compared to experimental data ${ }^{68}$ (red).

2.3 Vibrational entropies. Vibrational entropies are obtained using empirical potentials, with the General Utility Lattice Program (GULP) ${ }^{66}$ together with the Cooper, Rushton and Grimes $(\mathrm{CRG})^{33,67}$ potential. This is a many-body potential model used to describe actinide oxide systems which achieves good reproduction of thermodynamic and mechanical properties. The phonon density of states (DOS) for $\mathrm{PuO}_{2}$, calculated with the CRG potential and compared to the experimental data of Manley et al. ${ }^{68}$ is shown in Fig. 4. The calculated phonon DOS compares reasonably well to the experimental data. Many of the characteristic peaks and troughs are replicated, although at high frequency the magnitude of these features is smaller for the calculated data. This is a result of adopting a large $k$-point mesh that smooths the phonon DOS, and at high frequencies the experimental data has wide error bars. ${ }^{68}$ The calculation of vibrational entropies, $S_{\text {vib }}$, closely follows the approach described in ref. 36, 69 and 70, where using eqn (8), defect entropies are calculated from the normal vibrational frequencies, $v_{n}$, which are themselves calculated by diagonalizing the dynamical matrix of the system.

$$
S_{\mathrm{vib}}=-k_{\mathrm{B}} \sum_{n=1}^{3 N-1} \ln \left(\frac{h v_{n}}{k_{\mathrm{B}} T}\right)+(3 N-3) k_{\mathrm{B}}
$$

In this formula, $h$ is Plancks's constant and $N$ is the number of atoms in the crystal. In this study, the system to calculate vibrational

Table 2 The difference in vibrational entropy of $\mathrm{PuO}_{2}$ due to the addition of a defect, calculated using the CRG potential

\begin{tabular}{lllll}
\hline & \multicolumn{4}{l}{ Defect entropy, $\Delta S_{\mathrm{vib}} / k_{\mathrm{B}}$} \\
\cline { 2 - 5 }$T(\mathrm{~K})$ & $\mathrm{V}_{\mathrm{O}}$ & $\mathrm{O}_{\mathrm{i}}$ & $\mathrm{V}_{\mathrm{Pu}}$ & $\mathrm{Pu}_{\mathrm{i}}$ \\
\hline 400 & 0.545 & 4.572 & -3.783 & 2.518 \\
600 & -0.453 & 5.373 & -5.245 & 3.110 \\
800 & -1.230 & 6.058 & -6.208 & 3.725 \\
1000 & -1.868 & 6.638 & -6.940 & 4.270 \\
1200 & -2.391 & 7.137 & -7.508 & 4.746 \\
1400 & -2.843 & 7.578 & -7.996 & 5.164 \\
1600 & -3.238 & 7.961 & -8.402 & 5.547 \\
1800 & -3.574 & 8.309 & -8.761 & 5.883 \\
2000 & -3.899 & 8.599 & -9.086 & 6.174
\end{tabular}

entropies is a $4 \times 4 \times 4$ expansion of the $\mathrm{PuO}_{2}$ unit cell. Defective supercells are created by adding or removing atoms and are relaxed under constant volume in the same way as in the DFT simulations. Defect vibrational entropies are found by calculating the difference in vibrational entropies between the defective and perfect supercell $\left(\Delta S_{\mathrm{vib}}\right)$ and presented in Table 2 . The same value of $\Delta S_{\text {vib }}$ is given to all charge states of a given defect.

\subsection{Chemical potentials}

The starting point for determining the chemical potentials is to define the chemical potential of solid $\mathrm{PuO}_{2}\left(\mu_{\mathrm{PuO} 2(\mathrm{~s})}\right)$ in terms of the chemical potential per formula unit of the constituent species, namely plutonium, $\mu_{\mathrm{Pu}}\left(P_{\mathrm{O} 2}, T\right)$, and oxygen, $\mu_{\mathrm{O} 2}\left(P_{\mathrm{O} 2}, T\right)$ :

$$
\mu_{\mathrm{Pu}}\left(P_{\mathrm{O} 2}, T\right)+\mu_{\mathrm{O} 2}\left(P_{\mathrm{O} 2}, T\right)=\mu_{\mathrm{PuO} 2(\mathrm{~s})}
$$

For a solid, $\mu\left(P_{\mathrm{O}_{2}}^{\circ}, T^{\circ}\right) \approx \mu(0,0)$, therefore the temperature and pressure dependencies have been dropped. In equilibrium conditions, the chemical potential of Pu cannot exceed that of solid $\mathrm{Pu}$, otherwise a $\mathrm{Pu}$ precipitate would form. This upper bound is the Gibbs free energy of Pu in its natural state. It can therefore be said that in $\mathrm{Pu}$ rich conditions:

$$
\mu_{\mathrm{Pu}}\left(P_{\mathrm{O}_{2}}, T\right)=\mu_{\mathrm{Pu}(\mathrm{s})}
$$

To find $\mu_{\mathrm{Pu}(\mathrm{s})}$ we simulate the $\alpha$ phase of Pu with DFT using PBEsol $+U$. We encompass the recommendation of the review by Söderlind et $a .^{71}$ to use small $U$ and $J$ values, setting $U$ and $J$ parameters at $2.2 \mathrm{eV}$ and $0.58 \mathrm{eV}$ respectively. The atomic volume obtained with these values $\left(18.27 \AA^{3}\right)$ matched closely the atomic volume obtained by Söderlind et al. ${ }^{71}$ when using $\mathrm{PBE}+U$. To determine the chemical potential of oxygen the approach of Finnis et $a l^{72}$ is adopted. This method uses the known experimental formation energy of the oxide $\left(\Delta H_{\mathrm{f}}^{\mathrm{PuO}_{2}}\left(P_{\mathrm{O}_{2}}^{\circ}, T^{\circ}\right)=-10.94 \mathrm{eV}\right)^{73}$ to obtain the chemical potential of oxygen at standard temperature and pressure:

$$
\Delta H_{\mathrm{f}}^{\mathrm{PuO}_{2}}\left(P_{\mathrm{O}_{2}}^{\circ}, T^{\circ}\right)=\mu_{\mathrm{PuO}_{2}(\mathrm{~s})}-\mu_{\mathrm{Pu}(\mathrm{s})}-\mu_{\mathrm{O}_{2}}\left(P_{\mathrm{O}_{2}}^{\circ}, T^{\circ}\right)
$$

Unlike the solid species in eqn (11), the temperature and pressure dependence of the oxygen chemical potential cannot be 
Table 3 Coefficients for Gibbs free energy expression in eqn $(13)^{74}$

\begin{tabular}{ll}
\hline$A$ & $29.659 \times 10^{-3} \mathrm{~kJ} \mathrm{~mol}^{-1} \mathrm{~K}^{-1}$ \\
$B$ & $6.137261 \times 10^{-6} \mathrm{~kJ} \mathrm{~mol}^{-1} \mathrm{~K}^{-1}$ \\
$C$ & $-1.186521 \times 10^{-9} \mathrm{~kJ} \mathrm{~mol}^{-1} \mathrm{~K}^{-1}$ \\
$D$ & $0.095780 \times 10^{-12} \mathrm{~kJ} \mathrm{~mol}^{-1} \mathrm{~K}^{-1}$ \\
$E$ & $-0.219663 \times 10^{-3} \mathrm{~kJ} \mathrm{~mol}^{-1} \mathrm{~K}^{-1}$ \\
$F$ & $-9.861391 \mathrm{~kJ} \mathrm{~mol}^{-1} \mathrm{~K}^{-1}$ \\
$G$ & $237.948 \times 10^{-3} \mathrm{~kJ} \mathrm{~mol}^{-1} \mathrm{~K}^{-1}$ \\
\hline
\end{tabular}

neglected and is extrapolated from $\mu_{\mathrm{O}_{2}}\left(P_{\mathrm{O}_{2}}^{\circ}, T^{\circ}\right)$ using formulas constructed by Johnston et al.: ${ }^{74}$

$$
\begin{aligned}
\mu_{\mathrm{O}_{2}}\left(P_{\mathrm{O}_{2}}, T\right)= & \mu_{\mathrm{O}_{2}}\left(P_{\mathrm{O}_{2}}^{\circ}, T^{\circ}\right)+G\left(P^{\circ}, T\right)-G\left(P^{\circ}, T^{\circ}\right) \\
& +k_{\mathrm{B}} T\left(\frac{P_{\mathrm{O}_{2}}}{P_{\mathrm{O}_{2}}^{\circ}}\right)
\end{aligned}
$$

where the temperature dependent Gibbs free energy per mole is fitted to a polynomial derived from experimental data (coefficients listed in Table 3): ${ }^{74}$

$$
\begin{aligned}
G\left(P^{0}, T\right)= & A(T-T \ln (T))-\frac{1}{2} B T^{2}-\frac{1}{6} C T^{3} \\
& -\frac{1}{12} D T^{4}-\frac{E}{2 T}+F-G T
\end{aligned}
$$

The electron chemical potential, $\mu_{\mathrm{e}}=E_{\mathrm{VBM}}+\varepsilon_{\mathrm{F}}$, is expressed as the sum of the energy of the valence band maximum (VBM), $E_{\mathrm{VBM}}$, and the electron chemical potential above the VBM, $\varepsilon_{\mathrm{F}}$. As overall charge neutrality of the system must be maintained, the concentrations of ionic and electronic defects must be such that at any given temperature and oxygen partial pressure the following criteria is met: ${ }^{75}$

$$
\begin{gathered}
\sum_{i} q_{i} c_{i}+\int_{-\infty}^{E_{\mathrm{VBM}}} g_{v}(E) \frac{\mathrm{d} E}{1+\exp \left(\frac{\varepsilon_{\mathrm{F}}-E}{k_{\mathrm{B}} T}\right)} \\
-\int_{E_{\mathrm{CBM}}}^{\infty} g_{\mathrm{c}}(E) \frac{\mathrm{d} E}{1+\exp \left(\frac{E-\varepsilon_{\mathrm{F}}}{k_{\mathrm{B}} T}\right)}=0
\end{gathered}
$$

The first term is the sum of the charges the of ionic defects. The second and third terms are given by applying Fermi-Dirac statistics to the electronic DOS to obtain the concentrations of electrons $\left(\mathrm{e}^{-}\right)$in the conduction band and concentration of holes $\left(\mathrm{p}^{-}\right)$in the valence band, respectively. Within these two integrals are $g_{\mathrm{v}}(E)$ and $g_{\mathrm{c}}(E)$, the density of electronic states in the valence band and conduction band per formula unit of $\mathrm{PuO}_{2}$, respectively. For calculation of the electron population, $E_{\mathrm{CBM}}$ is the energy of the conduction band minimum.

With the above expressions it is possible to construct diagrams showing the variation of defect concentrations with environmental conditions; at each condition there exists a unique value of $\varepsilon_{\mathrm{F}}$ that satisfies the charge neutrality condition. The Defect Analysis Package ${ }^{76}$ employs a linear bisection to find the value of $\varepsilon_{\mathrm{F}}$ that ensures charge neutrality for any given oxygen partial pressure and temperature. Additionally, the deviation from stoichiometry, $x$ in
$\mathrm{PuO}_{2 \pm x}$, is calculated from the defect concentrations summed over all charge states:

$$
x=\frac{2+\left[\mathrm{O}_{\mathrm{i}}\right]-\left[\mathrm{V}_{\mathrm{O}}\right]}{1+\left[\mathrm{Pu}_{\mathrm{i}}\right]-\left[\mathrm{V}_{\mathrm{Pu}}\right]}-2
$$

\section{Results \& discussions}

The formation energy of all defects considered are plotted as a function of the Fermi level in Fig. 5. Fig. 5 shows the formation energies at $1000 \mathrm{~K}$ and O-rich $\left(10^{-2} \mathrm{~atm}\right) / \mathrm{O}-$ poor $\left(10^{-30} \mathrm{~atm}\right)$ conditions, displaying only the charge state of each defect that corresponds to the lowest formation energy at a given position in the bandgap. Under O-rich conditions $\mathrm{Pu}_{\mathrm{i}}$ defects have very high formation energy and so are not shown in Fig. 5. For each defect it can be seen that, to varying degrees, the charge state with the lowest energy varies across the bandgap. $V_{\mathrm{Pu}}$ defects have the least variation, its full ionic charge state $\left(\mathrm{V}_{\mathrm{Pu}}^{4-}\right)$ has the lowest energy across the majority of the bandgap. Conversely, under halfway across the bandgap, the neutral $V_{O}^{\times}$defect is seen to overtake the fully charged $\mathrm{V}_{\mathrm{O}}^{2+}$ defect as the oxygen vacancy with the lowest formation energy. Prodan et al. ${ }^{21}$ report that $\mathrm{O}_{\mathrm{i}}^{1-}$ is the most energetically favourable charge state for the oxygen interstitial. We find that although the $\mathrm{O}_{\mathrm{i}}^{2-}$ defect has the lowest energy for much of the bandgap, $\mathrm{O}_{\mathrm{i}}^{1-}$ becomes favourable at low Fermi level values, with $\mathrm{O}_{\mathrm{i}}^{\times}$most favourable at the lowest Fermi levels close to the valence band. Therefore, under certain conditions we also find $\mathrm{O}_{\mathrm{i}}^{1-}$ to be the preferred interstitial. Across the band gap the favourable charge state of $\mathrm{Pu}_{\mathrm{i}}$ defects are seen to vary, with each charge state except $\mathrm{Pu}_{\mathrm{i}}^{2+}$ possessing the lowest formation energy over fairly large ranges in Fermi level.

Table 4 displays the calculated reaction energy of unbound oxygen and plutonium Frenkel pairs (FP) and the unbound Schottky tri-vacancy (STV), with defects formally charged. Each reaction energy is found to be within the range of previous theoretical calculations, which are provided for comparison in Table 4 . The ranges are seen to be very wide; in the $\mathrm{DFT}+U$ studies, the $U$ and $J$ parameters adopted varied significantly indicating the importance of electron repulsion of the $5 \mathrm{f}$ electrons on the formation of point defects. The review of Murch et al. ${ }^{77}$ provides the only experimental comparison available, indicating that the oxygen Frenkel pair has a much lower formation energy than calculated here. Caution is however attached to the oxygen Frenkel pair experimental result, which is described by Murch et al. ${ }^{77}$ as "on the low side". Our results match the established pattern in all techniques, where O-FP $<$ STV $<$ Pu-FP, showing that oxygen-type defects are significantly more favourable than plutonium-type defects.

The resulting point defect concentrations, calculated as a function of temperature at a fixed oxygen partial pressure of $10^{-5} \mathrm{~atm}$, are presented in Fig. 6. Concentrations of oxygen defects are observed to be multiple orders of magnitude greater than cation defect concentrations across all temperatures. This agrees with previous experimental work that metal defects are 

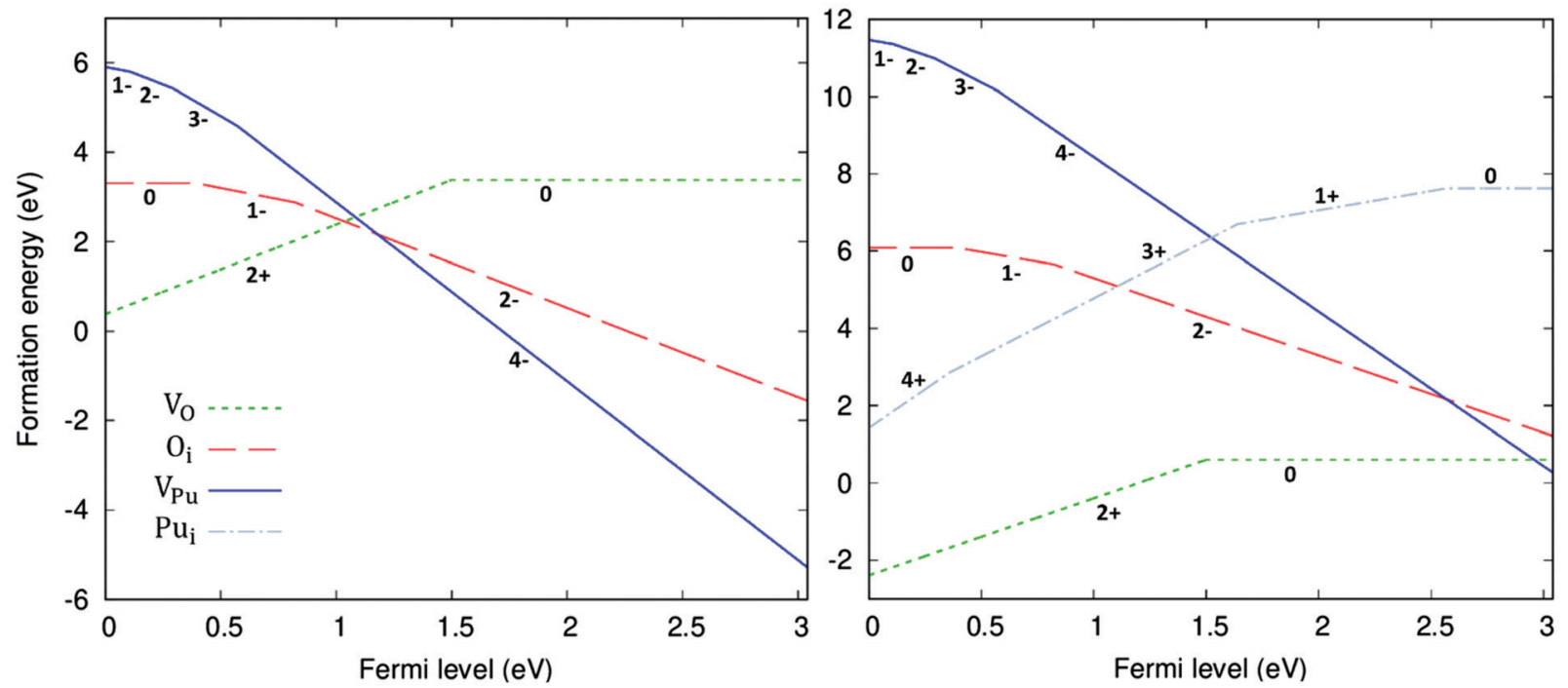

Fig. 5 Defect formation energies for $\mathrm{O}$ vacancies $\&$ interstitials as well as Pu vacancies $\&$ interstitials as a function of Fermi energy. Calculated at $1000 \mathrm{~K}$ and oxygen partial pressure of $10^{-2} \mathrm{~atm}$ (left) and $10^{-30} \mathrm{~atm}$ (right). Only the charge state with the lowest formation energy for a given Fermi level is shown for each defect, represented with numeric label. At an oxygen partial pressure of $10^{-2} \mathrm{~atm} \mathrm{Pu}$ interstitials are omitted from the plot as their formation energy is very high.

minority defects in $\mathrm{PuO}_{2} \cdot{ }^{77}$ All plutonium vacancy and interstitial defects are predicted to have such low concentrations that do not appear in Fig. 6.

Fig. 6 also displays the impact of including vibrational entropy contributions. Inclusion of vibrational entropy is seen to increase the temperature at which perfect stoichiometry occurs: $\approx 1200 \mathrm{~K}$ when vibrational entropy is omitted versus $\approx 1425 \mathrm{~K}$ when included. Perfect stoichiometry occurs when $\left[\mathrm{O}_{\mathrm{i}}\right]=\left[\mathrm{V}_{\mathrm{O}}\right]$, meaning that vibrational entropy inclusion further promotes $\mathrm{O}_{i}$ defects. From the point of perfect stoichiometry, increasing or decreasing temperature results in hypostoichiometric or hyper-stoichiometric $\mathrm{PuO}_{2 \pm x}$, respectively. The diagrams display the reluctance for $\mathrm{PuO}_{2}$ to be hyperstoichiometric in oxygen, with $x$ in $\mathrm{PuO}_{2+x}$ peaking at approx. $10^{-7}$ at $1210 \mathrm{~K}$ (when vibrational entropy included), representing negligible hyper-stoichiometry. As temperature decreases from this peak, the concentration of defects and the value of $x$ in $\mathrm{PuO}_{2+x}$ falls. The concentration of defects becomes increasingly negligible; this continues beyond the range of Fig. 6, at lower temperatures. It can be seen hypo-stoichiometry is much more favourable, which correlates with the wide hypo-stoichiometric region evident in the phase diagram of $\mathrm{PuO}_{2}{ }^{78}$
From this point onwards, all plots include vibrational entropy. Broadly speaking, the diagram in Fig. 6 can be broken down into three regions based upon electron and hole concentrations: these are a hole-dominant region, a region of equal concentration and an electron dominant region. At low temperatures the $\mathrm{O}_{\mathrm{i}}$ defects dominate and are charge compensated by holes. The $\left[\mathrm{O}_{\mathrm{i}}\right]:\left[\mathrm{p}^{+}\right]$ratio is approximately $1: 2$, due to the dominance of the $\mathrm{O}_{\mathrm{i}}^{2-}$ defect. Increasing the temperature past the point of peak-hyper-stoichiometry, which coincides with peak $\left[\mathrm{O}_{\mathrm{i}}\right]$, the hole concentration is no longer set such that it provides charge compensation to $\mathrm{O}_{\mathrm{i}}$ defects. Instead, the concentration of holes matches the concentration of electrons and the Fermi level remains fixed at the midpoint of the bandgap. $\left[\mathrm{V}_{\mathrm{O}}\right]$ increases with temperature, resulting in increasing hypo-stoichiometry. At high temperatures, $\left[\mathrm{V}_{\mathrm{O}}\right]$ reaches levels close to the concentration of holes and electrons. To accommodate any further increases in $\left[\mathrm{V}_{\mathrm{O}}\right]$, the concentration of electrons increases to maintain charge neutrality. The concentration of holes then decreases as the temperature increases resulting in the Fermi level increasing. In this region, the $\left[\mathrm{V}_{\mathrm{O}}\right]:\left[\mathrm{e}^{-}\right]$ratio varies in order to provide charge compensation to both $\mathrm{V}_{\mathrm{O}}^{2+}$ and $\mathrm{V}_{\mathrm{O}}^{1+}$ defects.

Table 4 Reaction energies for the intrinsic processes in $\mathrm{PuO}_{2}$ with comparison to experimental and previous theoretical studies. Theoretical studies are separated further, based on if results are obtained using DFT or empirically

\begin{tabular}{|c|c|c|c|c|c|c|c|c|c|c|}
\hline \multirow[b]{2}{*}{ Process } & \multirow[b]{2}{*}{ Charge states } & \multicolumn{9}{|c|}{ Reaction energy (eV) } \\
\hline & & This work & $\mathrm{LSDA}+U^{24}$ & $\mathrm{LDA}+U^{30}$ & $\mathrm{GGA}+U^{31}$ & $\mathrm{GGA}+U^{32}$ & Ref. 26 & Ref. 27 & Ref. 32 & $\frac{\text { Experiment }}{\text { O diffusion }^{77}}$ \\
\hline O Frenkel pair & $\mathrm{V}_{\mathrm{O}}^{2+}+\mathrm{O}_{\mathrm{i}}^{2-}$ & 4.89 & 3.48 & 4.58 & 9.78 & 3.90 & 5.52 & 2.66 & 4.90 & $2.72-2.92$ \\
\hline Pu Frenkel pair & $\mathrm{V}_{\mathrm{Pu}}^{4-}+\mathrm{Pu}_{\mathrm{i}}^{4+}$ & 13.86 & 15.19 & 10.02 & 19.78 & 11.90 & 13.58 & 10.03 & 24.00 & \\
\hline Schottky defect & $\mathrm{V}_{\mathrm{Pu}}^{4-}+2 \mathrm{~V}_{\mathrm{O}}^{2+}$ & 7.65 & 7.51 & 6.09 & 14.92 & & 10.40 & 3.54 & & \\
\hline
\end{tabular}



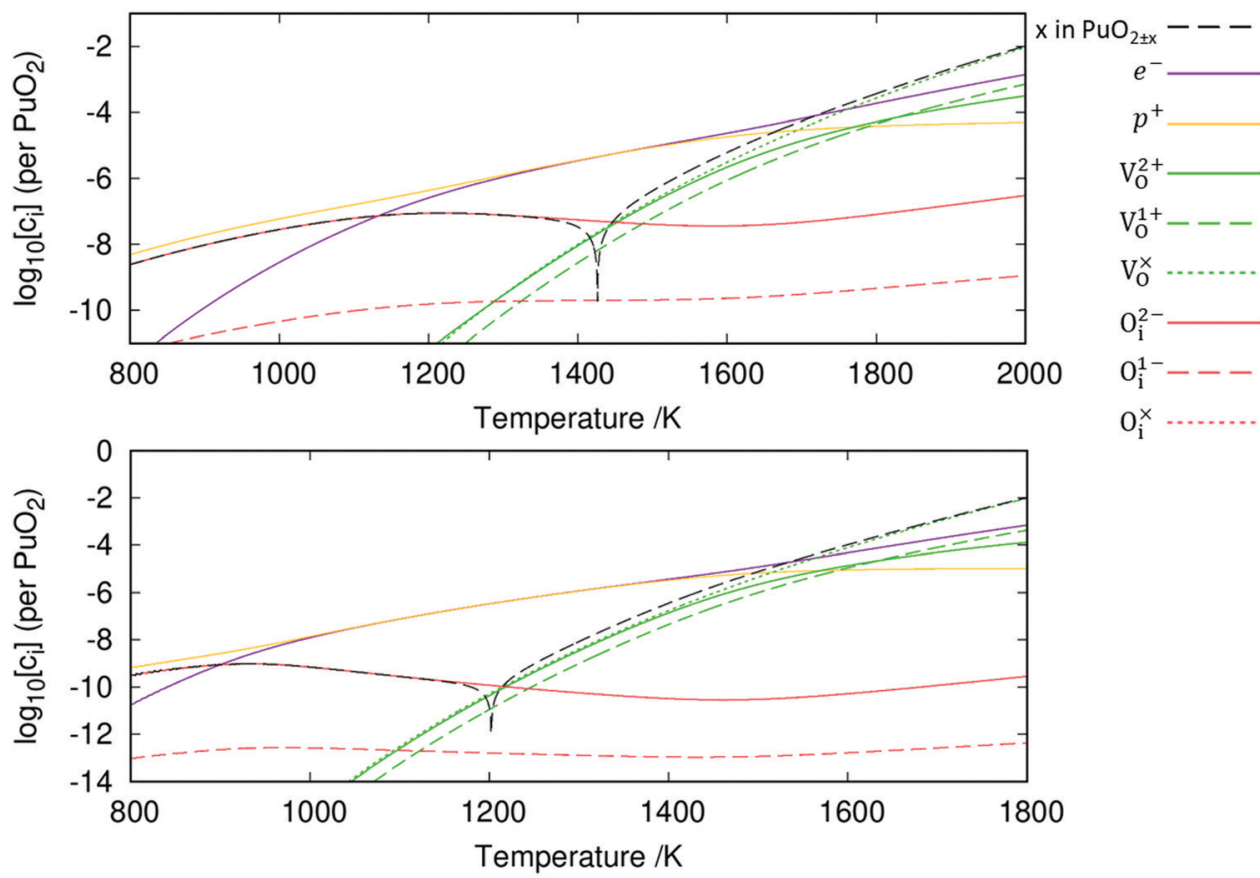

Fig. 6 The defect chemistry of $\mathrm{PuO}_{2 \pm x}$ as a function of temperature at an oxygen partial pressure of $10^{-5}$ atm. The diagrams include (top) and exclude (bottom) vibrational entropy contributions when calculating defect concentrations.

The defect chemistry of $\mathrm{PuO}_{2}$ as a function of oxygen partial pressure is presented in the Brouwer diagrams of Fig. 7, at temperatures $1000 \mathrm{~K}$ and $2000 \mathrm{~K}$. At $1000 \mathrm{~K}$, in the region close to perfect stoichiometry, where $x$ in $\mathrm{PuO}_{2 \pm x}$ is at its smallest, $\mathrm{O}_{\mathrm{i}}^{2-}$ is the dominant oxygen interstitial. The dominant oxygen vacancies are found to be $\mathrm{V}_{\mathrm{O}}^{2+}$ and $\mathrm{V}_{\mathrm{O}}^{\times}$, which have concentrations of similar magnitude, with $V_{O}^{\times}$at narrowly higher concentrations. In this region of near-stoichiometry, the defect chemistry and dependence on oxygen partial pressure can be attributed to the following defect reactions occurring:

$$
\begin{gathered}
\frac{1}{2} \mathrm{O}_{2(\mathrm{~g})}+\mathrm{e}^{-} \rightleftharpoons \mathrm{O}_{\mathrm{i}}^{2-}+\mathrm{p}^{+} \\
\mathrm{O}_{\mathrm{O}}^{\times}+\mathrm{p}^{+} \rightleftharpoons \mathrm{V}_{\mathrm{O}}^{2+}+\mathrm{e}^{-}+\frac{1}{2} \mathrm{O}_{2(\mathrm{~g})} \\
\mathrm{O}_{\mathrm{O}}^{\times} \rightleftharpoons \mathrm{V}_{\mathrm{O}}^{\times}+\frac{1}{2} \mathrm{O}_{2(\mathrm{~g})}
\end{gathered}
$$

Application of the law of mass action to eqn (16), (17) and (18) finds equilibrium constants of $k_{1}, k_{2}$ and $k_{3}$, respectfully:

$$
\begin{gathered}
k_{1}=\left[\mathrm{O}_{\mathrm{i}}^{2-}\right]\left[\mathrm{p}^{+}\right]\left[\mathrm{e}^{-}\right]^{-1}\left[P_{\mathrm{O}_{2}}\right]^{-\frac{1}{2}} \\
k_{2}=\left[\mathrm{V}_{\mathrm{O}}^{2+}\right]\left[\mathrm{e}^{-}\right]\left[\mathrm{p}^{+}\right]^{-1}\left[P_{\mathrm{O}_{2}}\right]^{\frac{1}{2}} \\
k_{3}=\left[\mathrm{V}_{\mathrm{O}}^{\times}\right]\left[\mathrm{P}_{\mathrm{O}_{2}}\right]^{\frac{1}{2}}
\end{gathered}
$$

Given that $\left[\mathrm{e}^{-}\right]=\left[\mathrm{p}^{+}\right]$, it can be seen that $\left[\mathrm{O}_{\mathrm{i}}^{2-}\right]$ is proportional to $P_{\mathrm{O}_{2}}^{\frac{1}{2}}$, whilst $\left[\mathrm{V}_{\mathrm{O}}^{2+}\right]$ and $\left[\mathrm{V}_{\mathrm{O}}^{\times}\right]$are proportional to $P_{\mathrm{O}_{2}}^{-\frac{1}{2}}$ in this region. Increasing the oxygen partial pressure beyond the region of near-stoichiometry sees the concentration holes, $\mathrm{O}_{\mathrm{i}}^{2-}$ defects and $x$ in $\mathrm{PuO}_{2+x}$ transition to an oxygen partial pressure dependence of $P_{\mathrm{O}_{2}}^{-\frac{1}{6}}$. With too few electrons available, two holes are created for charge compensation of the $\mathrm{O}_{\mathrm{i}}^{2-}$ defect. Eqn (22) and (23) show the defect reaction responsible and the corresponding equilibrium constant, respectively. Given that $\left[\mathrm{O}_{\mathrm{i}}^{2-}\right]=2\left[\mathrm{p}^{+}\right]$, it can be shown using eqn (23) that $\left[\mathrm{O}_{\mathrm{i}}^{2-}\right]$ is proportional to $P_{\mathrm{O}_{2}}^{\frac{1}{6}}$ in the hyper-stoichiometric region.

$$
\begin{aligned}
& \frac{1}{2} \mathrm{O}_{2(\mathrm{~g})} \rightleftharpoons \mathrm{O}_{\mathrm{i}}^{2-}+2 p^{+} \\
& k_{4}=\left[\mathrm{O}_{\mathrm{i}}^{2-}\right]\left[p^{+}\right]^{2}\left[P_{\mathrm{O}_{2}}\right]^{-\frac{1}{2}}
\end{aligned}
$$

Reducing the oxygen partial pressure below the region of near-stoichiometry sees the concentration of $\mathrm{V}_{\mathrm{O}}^{2+}$ defects transition to a dependence on the oxygen partial pressure of $P_{\mathrm{O}_{2}}^{-\frac{1}{6}}$, whilst concentration of $\mathrm{V}_{\mathrm{O}}^{\times}$defects maintain a dependence on the oxygen partial pressure of $P_{\mathrm{O}_{2}}^{-\frac{1}{2}}$. Consequently, it is eqn (18) that is the dominant defect reaction in the hypo-stoichiometric region, causing $\mathrm{V}_{\mathrm{O}}^{\times}$defects to become the dominant defect and the source of hypo-stochiometric $\mathrm{PuO}_{2-x}$. The dependence of $x$ in $\mathrm{PuO}_{2-x}$ has been shown experimentally to have a dependence on the oxygen partial pressure of $P_{\mathrm{O}_{2}}^{-\frac{1}{4}}, 35$ indicative of the $\mathrm{V}_{\mathrm{O}}^{1+}$ vacancy being dominant. This result reflects experimental data at large non-stoichiometry, where the point defect model breaks down due to the occurrence of complex processes 

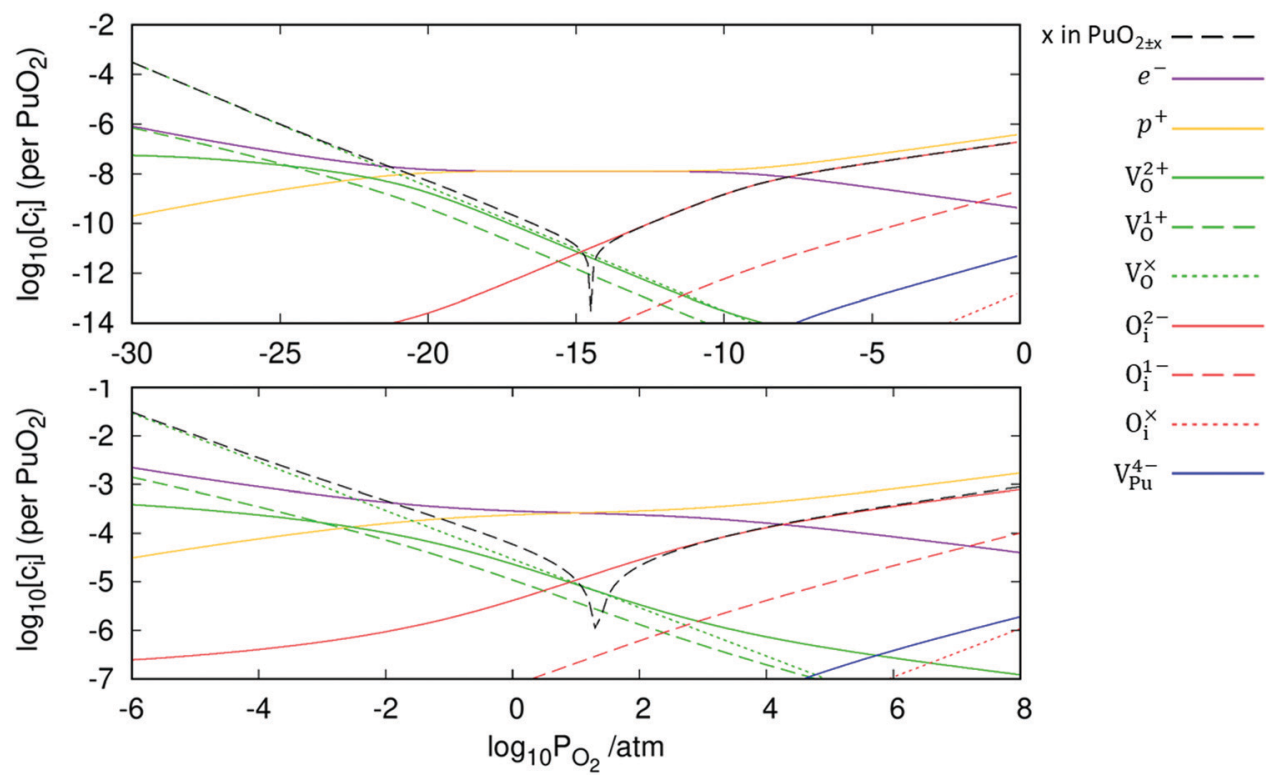

Fig. 7 Calculated Brouwer diagram showing the defect chemistry of $\mathrm{PuO}_{2 \pm x}$ as a function of the oxygen partial pressure at $1000 \mathrm{~K}$ (top) and $2000 \mathrm{~K}$ (bottom). Both diagrams include vibrational entropy contributions when calculating defect concentrations.

involving defect clusters. Our result, that reflects very small non-stoichiometry, can therefore not be directly compared.

Comparing the two Brouwer diagrams in Fig. 7, increasing temperature creates a more reducing environment, increasing oxygen vacancy concentrations. Perfect stoichiometry therefore occurs at higher oxygen partial pressures. Aside from this, in the $1000 \mathrm{~K}$ temperature range investigated here, temperature is found not to alter the defect chemistry of $\mathrm{PuO}_{2}$ significantly.

The finding that the defect chemistry of $\mathrm{PuO}_{2}$ is dominated by oxygen interstitials and vacancies agrees with the predictions in the $\mathrm{PuO}_{2}$ point defect study of Lu et al. ${ }^{24}$ However, the present study has found a significant increase in the concentrations of non-formally charged defects relative to their formally charged counterparts. Whereas Lu et al. ${ }^{24}$ found $\left[\mathrm{O}_{\mathrm{i}}^{2-}\right]$ and $\left[\mathrm{V}_{\mathrm{O}}^{2+}\right]$ defects to be multiple orders of magnitude greater than any non-formally charged defect, here $\mathrm{V}_{\mathrm{O}}^{\times}$is the dominant oxygen vacancy and concentration of $\mathrm{O}_{\mathrm{i}}^{1-}$ is predicted to be much closer to that of $\mathrm{O}_{\mathrm{i}}^{2-}$. This can be partially attributed to the larger bandgap used in this work (3.04 eV vs. $1.70 \mathrm{eV}$ ). Electrons and holes, which are required to provide charge compensation to charged defects, have an increased formation energy with increased band gap. Therefore, increasing the bandgap increases the favourability of defects with a smaller charge magnitude. Additionally, we report a much lower degree of hyper-stoichiometry. For example, at a temperature of $1000 \mathrm{~K}$ and oxygen partial pressure of $10^{-5} \mathrm{~atm}$ Lu et al. ${ }^{24}$ report a value of $\mathrm{x}$ in $\mathrm{PuO}_{2+x}$ of $\approx 10^{-3}$, several orders of magnitude greater than the value of $\approx 10^{-6}$ found in this study.

\section{Conclusions}

In summary, using $\mathrm{DFT}+U$ with a longitudinal 3k AFM magnetic structure and SOI, the point defect concentrations in $\mathrm{PuO}_{2 \pm x}$ as a function of temperature and oxygen partial pressure have been determined. The results predict that the defect chemistry of $\mathrm{PuO}_{2}$ is dominated by oxygen vacancies and interstitials, but that even at high oxygen partial pressures, $\mathrm{PuO}_{2}$ is found reluctant to form hyper-stoichiometric $\mathrm{PuO}_{2+x}$, with oxygen interstitials present only in very low concentrations irrespective of conditions. Hypo-stoichiometric $\mathrm{PuO}_{2-x}$ is predicted, in agreement with the $\mathrm{PuO}_{2}$ phase diagram, ${ }^{78}$ and is accommodated by both the $\mathrm{V}_{\mathrm{O}}^{\times}$and $\mathrm{V}_{\mathrm{O}}^{2+}$ defects at small values of $x$, with $\mathrm{V}_{\mathrm{O}}^{\times}$ increasingly dominant with increasing $x$. The little hyperstoichiometry is accommodated by the $\mathrm{O}_{\mathrm{i}}^{2-}$ defect. Aside from increasing the temperature at which perfect stoichiometry occurs, inclusion of vibrational entropy into the defect formation energy calculation was not found to alter which defects accommodate non-stoichiometry in $\mathrm{PuO}_{2 \pm x}$, as observed in $\mathrm{UO}_{2} \cdot{ }^{36,37}$

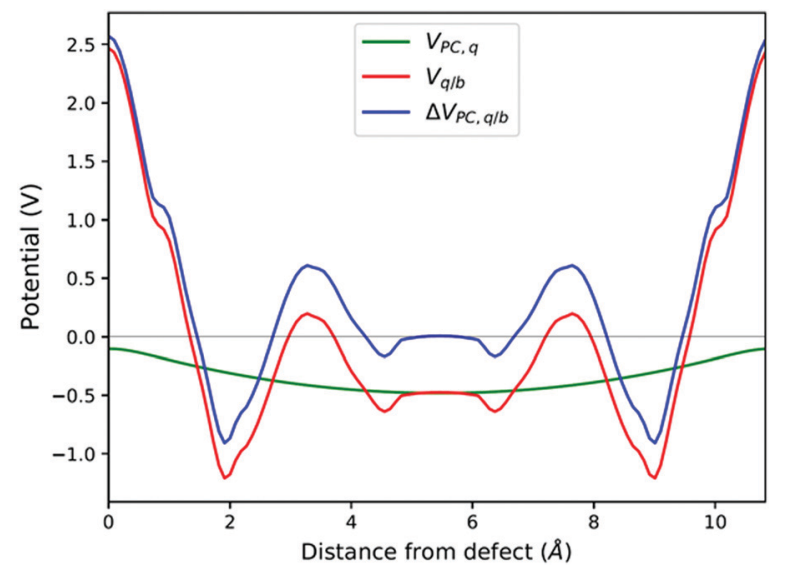

Fig. 8 Planar averaged $V_{\mathrm{q} / \mathrm{b}}, V_{\mathrm{PC}, \mathrm{q}}$ and $\Delta V_{\mathrm{PC}, \mathrm{q} / \mathrm{b}}$ calculated at the atomic positions of $\mathrm{a}_{\mathrm{PuO}}$ supercell with a $\mathrm{V}_{\mathrm{Pu}}{ }^{4-}$ defect. 


\section{Conflicts of interest}

There are no conflicts to declare.

\section{Appendix}

See Fig. 8.

\section{Acknowledgements}

We thank D. O. Scanlon and M. Pacey for their valuable help. This work made use of the High End Computing facility at Lancaster University. The visualisation of crystal structures was performed with VESTA, ${ }^{79}$ finite-size corrections were calculated using pymatgen. ${ }^{80}$ This project was funded as part of EPSRCs TRANSCEND project (EP/S01019X/1).

\section{References}

1 J. M. Haschke and J. L. Stakebake, Handling, Storage, and Disposition of Plutonium and Uranium, in The Chemistry of the Actinide and Transactinide Elements, ed. L. R. Morss, N. M. Edelstein and J. Fuger, Springer, Dordrecht, 3rd edn, 2010, vol. 5, ch. 29, pp. 3199-3272.

2 R. C. O’Brien, R. M. Ambrosi, N. P. Bannister, S. D. Howe and H. V. Atkinson, J. Nucl. Mater., 2008, 377, 506-521.

3 G. Bailey, E. Bluhm, J. Lyman, R. Mason, M. Paffet, G. Polansky, G. D. Roberson, M. Sherman, K. Veirs and L. Worl, Gas Generation from Actinide Oxide Materials, LA-13781-MS, Los Alamos National Laboratory, Los Alamos, NM, 2000.

4 J. M. Haschke, T. H. Allen and L. A. Morales, Science, 2000, 287, 285-287.

5 J. M. Haschke and T. H. Allen, J. Alloys Compd., 2002, 336, 124-131.

6 J. M. Haschke, T. H. Allen and L. A. Morales, J. Alloys Compd., 2001, 314, 78-91.

7 J. D. Farr, R. K. Schulze and M. P. Neu, J. Nucl. Mater., 2004, 328, 124-136.

8 S. T. Conradson, B. D. Begg, D. L. Clark, C. den Auwer, M. Ding, P. K. Dorhout, F. J. Espinosa-Faller, P. L. Gordan, R. G. Haire, N. J. Hess, R. F. Hess, D. Webster Keogh, L. A. Morales, M. P. Neu, P. Paviet-Hartmann, W. Runde, C. Drew Tait, D. Kirk Veirs and P. M. Villella, J. Am. Chem. Soc., 2004, 126, 13443-13458.

9 Los Alamos Science, ed. N. G. Cooper, Los Alamos National Laboratory, Los Alamos, NM, 2000, vol. 26.

10 X.-D. Wen, R. L. Martin, T. M. Henderson and G. E. Scuseria, Chem. Rev., 2013, 113, 1063-1096.

11 J. T. Pegg, X. Aparicio-Anglès, M. Storr and N. H. de Leeuw, J. Nucl. Mater., 2017, 492, 269-278.

12 S. L. Dudarev, G. A. Botton, S. Y. Savrasov, C. J. Humphreys and A. P. Sutton, Phys. Rev. B: Condens. Matter Mater. Phys., 1998, 57, 1505.

13 P. S. Ghosh and A. Arya, Phys. Chem. Chem. Phys., 2019, 21, 16818-16829.
14 J. T. Pegg, A. E. Shields, M. T. Storr, A. S. Wills, D. O. Scanlon and N. H. de Leeuw, Phys. Chem. Chem. Phys., 2018, 20, 20943-20951.

15 H. Nakamura, M. Machida and M. Kato, Prog. Nucl. Sci. Technol, 2011, 2, 16-19.

16 P. Zhang, B.-T. Wang and X.-G. Zhao, Phys. Rev. B: Condens. Matter Mater. Phys., 2010, 82, 144110.

17 B. Sun, P. Zhang and X.-G. Zhao, J. Chem. Phys., 2008, 128, 084705.

18 C. E. McNeilly, J. Nucl. Mater., 1964, 11, 53-58.

19 T. M. McCleskey, E. Bauer, Q. Jia, A. K. Burrell, B. L. Scott, S. D. Conradson, A. Mueller, L. Roy, X. Wen, G. E. Scuseria and R. L. Martin, J. Appl. Phys., 2013, 113, 013515.

20 A. J. Garza and G. E. Scuseria, J. Phys. Chem. Lett., 2016, 7, 4165-4170.

21 I. D. Prodan and G. E. Scuseria, J. Chem. Phys., 2005, 123, 014703.

22 Y. Tokunaga, H. Sakai, T. Fujimoto, S. Kambe, R. E. Walstedt, K. Ikushima, H. Yasuoka, D. Aoki, Y. Homma, Y. Haga, T. D. Matsuda, S. Ikeda, E. Yamamoto, A. Nakamura, Y. Shiokawa, K. Nakajima, Y. Arai and Y. Ōnuki, J. Alloys Compd., 2007, 444-445, 241-245.

23 D. Gryaznov, E. Heifets and D. Sedmidubsky, Phys. Chem. Chem. Phys., 2010, 12, 12273-12278.

24 Y. Lu, Y. Yang and P. Zhang, J. Alloys Compd., 2015, 649, 544-552.

25 G. Jomard, B. Amadon, F. Bottin and M. Torrent, Phys. Rev. B: Condens. Matter Mater. Phys., 2008, 78, 075125.

26 S. C. Hernandez and E. F. Holby, J. Phys. Chem. C, 2016, 120, 13095-13102.

27 D. L. Clark, S. S. Hecker, G. D. Jarvinen and M. P. Neu, Plutonium, in The Chemistry of the Actinide and Transactinide Elements, ed. L. R. Morss, N. M. Edelstein and J. Fuger, Springer, Dordrecht, 3rd edn, 2008, vol. 2, ch. 7, pp. 813-1264.

28 L.-F. Wang, B. Sun, H.-F. Liu, D.-Y. Lin and H.-F. Song, J. Nucl. Mater., 2019, 526, 151762.

29 M. S. D. Read, S. R. Walker and R. A. Jackson, J. Nucl. Mater., 2014, 448, 20-25.

30 H. Nakamura and M. Machida, Prog. Nucl. Sci. Technol, 2018, 5, 132-135.

31 X. Tian, T. Gao, C. Lu, J. Shang and H. Xiao, Eur. Phys. J. B, 2013, 86, 179.

32 P. Tiwary, A. van de Walle, B. Jeon and N. Grønbech-Jensen, Phys. Rev. B: Condens. Matter Mater. Phys., 2011, 83, 094104.

33 M. W. D. Cooper, M. J. D. Rushton and R. W. Grimes, J. Phys.: Condens. Matter, 2014, 26, 105401.

34 M. Stan and P. Cristea, Defects and oxygen diffusion in $\mathrm{PuO}_{2-x}$, J. Nucl. Mater., 2005, 344, 213-218.

35 M. Kato, H. Nakamura, M. Watanabe, T. Matsumoto and M. Machida, Defect Diffus. Forum, 2017, 375, 57-70.

36 M. W. D. Cooper, S. T. Murthy and D. A. Andersson, J. Nucl. Mater., 2018, 504, 251-260.

37 A. Soulie, F. Bruneval, M. Marinica, S. T. Murphy and J. Crocombette, Phy. Rev. Mater., 2018, 2, 083607.

38 G. Kresse and J. Hafner, Phys. Rev. B: Condens. Matter Mater. Phys., 1993, 47, 558. 
39 G. Kresse and J. Hafner, Phys. Rev. B: Condens. Matter Mater. Phys., 1994, 49, 14251.

40 G. Kresse and J. Furthmüller, Comput. Mater. Sci, 1996, 6, 15.

41 G. Kresse and J. Furthmüller, Phys. Rev. B: Condens. Matter Mater. Phys., 1996, 54, 11169.

42 P. E. Blochl, Phys. Rev. B: Condens. Matter Mater. Phys., 1994, 50, 17953.

43 G. Kresse and D. Joubert, Phys. Rev. B: Condens. Matter Mater. Phys., 1999, 59, 1758.

44 H. J. Monkhurst and J. D. Pack, Phys. Rev. B: Solid State, 1976, 49, 16223.

45 S. Steiner, S. Khmelevskyi, M. Marsmann and G. Kresse, Phys. Rev. B, 2016, 93, 224425.

46 J. Heyd, G. E. Scuseria and M. Ernzerhof, J. Chem. Phys., 2003, 118, 8207.

47 J. Heyd and G. E. Scuseria, J. Chem. Phys., 2004, 121, 1187. 48 J. Heyd Scuseria and G. E. Scuseria, J. Chem. Phys., 2006, 124, 219906.

49 A. V. Krukau, O. A. Vydrov, A. F. Izmaylov and G. E. Scuseria, J. Chem. Phys., 2006, 125, 224106.

50 J. P. Perdew, A. Ruzsinszky, G. I. Csonka, O. A. Vydrov, G. E. Scuseria, L. A. Constantin, X. Zhou and K. Burke, Phys. Rev. Lett., 2009, 100, 136406.

51 G. I. Csonka, J. P. Perdew, A. Ruzsinszky, P. H. T. Philipsen, S. Lebègue, J. Paier, O. A. Vydrov and J. G. Ángyán, Phys. Rev. B: Condens. Matter Mater. Phys., 2009, 79, 155107.

52 A. I. Liechtenstein, V. I. Anisimov and J. Zaanen, Phys. Rev. B: Condens. Matter Mater. Phys., 1995, 52, R5467(R).

53 A. Shick, J. Kolorenc, L. Havela, T. Gouder and R. Caciuffo, Phys. Rev. B: Condens. Matter Mater. Phys., 2014, 89, 041109.

54 F. A. Kröger and H. J. Vink, Solid State Phys., 1956, 3, 307-435.

55 T. Durrant, S. Murphy, M. B. Watkins and A. L. Shluger, J. Chem. Phys., 2018, 149, 024103.

56 M. Leslie and N. J. Gillan, J. Phys. C: Solid State Phys., 1985, 18, 973.

57 S. Baroni and R. Resta, Phys. Rev. B: Condens. Matter Mater. Phys., 1986, 33, 7017.

58 M. Gajdoš, K. Hummer, G. Kresse, J. Furthmüller and F. Bechstedt, Phys. Rev. B: Condens. Matter Mater. Phys., 2006, 73, 045112.

59 L. Manes and A. Barisic, Phys. Status Solidi, 1970, 3, 971.

60 N. Hampton, G. Saunders, J. Harding and A. Stoneham, J. Nucl. Mater., 1987, 149, 18-20.
61 M. S. Talla Noutack, G. Geneste, G. Jomard and M. Freyss, Phys. Rev. Mater., 2019, 3, 035001.

62 G. Makov and M. C. Payne, Phys. Rev. B: Condens. Matter Mater. Phys., 1995, 51, 4014.

63 C. Freysoldt, J. Neugebauer and C. G. Van, de Walle, Phys. Rev. Lett., 2009, 102, 016402.

64 Y. Kumagai and F. Oba, Phys. Rev. B: Condens. Matter Mater. Phys., 2014, 89, 195205.

65 H.-P. Komsa, T. T. Rantala and A. Pasquarello, Phys. Rev. B: Condens. Matter Mater. Phys., 2012, 86, 045112.

66 J. D. Gale, J. Chem. Soc., Faraday Trans., 1997, 93, 629-637.

67 M. W. D. Cooper, S. T. Murphy, M. J. D. Rushton and R. W. Grimes, J. Nucl. Mater., 2015, 461, 206-214.

68 M. Manley, J. Jeffries, A. Said, C. A. Marianetti, H. Cynn, B. M. Leu and M. A. Wall, Phys. Rev. B: Condens. Matter Mater. Phys., 2012, 85, 132301.

69 Y. Mishin, M. R. Sørensen and A. F. Voter, Philos. Mag. A, 2001, 81, 2591-2612.

70 D. A. Andersson, P. Garcia, X.-Y. Liu, G. Pastore, M. Tonks, P. Millett, B. Dorado, D. Gaston, D. Andrs, R. L. Williamson, R. C. Martineau, B. P. Uberuaga and C. R. Stanek, J. Nucl. Mater., 2014, 451, 225-242.

71 P. Söderlind, A. Landa and B. Sadigh, Adv. Phys., 2019, 68, $1-47$.

72 M. W. Finnis, A. Y. Lozovoi and A. Alavi, Annu. Rev. Mater. Res., 2005, 35, 167-207.

73 G. K. Johnson, E. H. Deventer, O. L. Kruger and W. N. Hubbard, J. Chem. Thermodyn., 1969, 1, 89-98.

74 K. Johnston, M. R. Castell, A. T. Paxton and M. W. Finnis, Phys. Rev. B: Condens. Matter Mater. Phys., 2004, 70, 085415.

75 M. Youseff and B. Yildiz, Phys. Rev. B: Condens. Matter Mater. Phys., 2012, 86, 144109.

76 S. T. Murphy and N. D. M. Hine, Chem. Mater., 2014, 26, 1629-1638.

77 G. E. Murch, C. Richard and A. Catlow, J. Chem. Soc., Faraday Trans. 2, 1987, 83, 1157-1169.

78 C. Guéneau, C. Chatillon and B. Sundman, J. Nucl. Mater., 2008, 378, 257-272.

79 K. Momma and F. Izumi, J. Appl. Crystallogr., 2011, 44, 1272-1276.

80 S. Ong, W. Richards, A. Jain, G. Hautier, M. Kocher, S. Cholia, D. Gunter, V. Chevrier, K. Persson and G. Ceder, Comput. Mater. Sci., 2013, 68, 314-319. 